\title{
ELECTRICAL AND MECHANICAL PROPERTIES OF PHENOLIC RESIN AND GIGANTOCHLOA APUS CARBON FIBER COMPOSITES
}

\author{
Agus Edy Pramono ${ }^{1 *}$, Indriyani Rebet ${ }^{1}$, Anne Zulfa $^{2}$ \\ ${ }^{1}$ Department of Mechanical Engineering, Politeknik Negeri Jakarta, Depok 16424, Indonesia \\ ${ }^{2}$ Department of Metallurgy and Material, Faculty of Engineering, Universitas Indonesia, Kampus \\ UI Depok, Depok 16424, Indonesia
}

(Received: September 2016 / Revised: May 2017 / Accepted: October 2017)

\begin{abstract}
This work revealed electrical and mechanical properties of phenolic resin composites made from Gigantochloa apus carbon fiber, or bamboo carbon fiber reinforced polymer (BCFRP) composites. Bamboo fibers were carbonized at a temperature of $800^{\circ} \mathrm{C}$, with a temperature rate of $4.2^{\circ} \mathrm{C} /$ minutes, held for 120 minutes. Carbon fibers were arranged in one direction. Phenolic resin weights were determined to be $5 \%$ to $10 \%$. Higher carbon fiber contents indicated higher electrical conductivity of the composite. Increased carbon fiber content tends to increase the tensile strength of the composite, although this result was unstable. Mechanical instability was caused by cracks and cavities formed between the fiber and the phenolic resin. Cracks primarily occurred at the interface between bamboo carbon fibers and phenolic resin. This was most likely caused by the intrusion of air at the time the phenolic resin was cast. This air became trapped in between the fiber surfaces. Bamboo carbon fiber is fragile and easily broken in both longitudinal and transverse directions. When an air bubble bursts between carbon fibers, the carbon fiber braid breaks up, causing electrical resistance in composites. Not all carbon fibers in phenolic resin disconnect this way; most still form the strands that can conduct electricity. These breaks are the cause of the instability of the electrical conductivity properties of the composite.
\end{abstract}

Keywords: Carbon fibers; Electrical conductivity; Gigantochloa apus; Phenolic resin; Tensile and impact strength

\section{INTRODUCTION}

This study will suggest alternatives in producing and utilizing carbon fiber for electrically conductive polymer composites. This research used Gigantochloa apus, a local bamboo plant in Indonesia. Raw material made of a continuous bamboo fiber was carbonized in a pyrolysis process at a temperature of $800^{\circ} \mathrm{C}$ in a continuous vacuum furnace. The bamboo carbon fiber was produced by the researchers in a laboratory. The bamboo carbon fiber was not an industrial or commercial product. Most researchers utilize industrial-made carbon materials that are commercially available. This research used state of art methods in the utilization of local bamboo materials. Carbonization process was conducted in the laboratory by the researchers. Phenolic and hardener was used as the adhesive matrix. The phenolic resin material was a commercial product. The purpose of this study is to explore the types of carbon composites that produce electrical conductivity and their mechanical properties.

Research on electrically conductive composites has been conducted for decades. Electrically conductive composites are made of two kinds of materials that have opposing electrical

\footnotetext{
* Corresponding author's email: aepram@yahoo.com, Tel. +62-21-7270078, Fax.+62-21-7270077

Permalink/DOI: https://doi.org/10.14716/ijtech.v8i5.874
} 
properties. One kind of material is electrically conductive, and the other is electrically nonconductive. Electrically conductive material is applied as filler and reinforcement to a matrix of the electrically non-conductive material to form the composite. This matrix is most commonly made of a polymer material. Electrically conductive material can be produced by carbonizing organic materials at high temperatures.

Nine types of carbon material have been studied to measure electric constraints. These carbon types were electrographite, active carbon, carbon black, acetylene-black, petroleum coke $\left(1400^{\circ} \mathrm{C}\right)$, petroleum coke $\left(1600^{\circ} \mathrm{C}\right)$, Babassu nut coke, and Eucalyptus lignin carbon. Electrical resistance was measured under constant pressure, using a resistance measuring device and circuit potentiometric. Sample volume was calculated from the sample thickness measured and a crosssectional area of the pressure chamber (Espinola et al., 1986).

Electrical conductivity of carbon nanotubes in an epoxy matrix has been investigated because increased electrical conductivity and homogenization has applications for aeronautics. Laminated carbon fiber/epoxy composites are a heterogeneous material, and electrical conductivity depends on the orientation of the carbon fiber layers within the mix (Lonjon et al., 2012).

The electrical conductivity of the activated carbon produced from wood has also been tested. Activated carbon in the form of compacted powder was then measured for electrical constraints. Conductivity measurement of powder requires compacted granules to ensure electrical contact. The paper deals with the electrical conductivity of a number of carbonaceous powders undergoing a low compaction. Compaction causes electrical conductivity because of the individual grains and connections between them, and such a combination creates a strong particle (Celzard et al., 2002).

Silicone is a polymer containing silicon, carbon, hydrogen, oxygen and other elements. When silicone is used as an electrical insulator, it can be made conductive by adding conductive material extrinsically. Two types of silicone rubber prepared with electrically conductive carbon fiber have shown the best results. Carbon fiber increases the electrical conductivity of the rubber, even at a very low percentage of weight (Saleem et al., 2010).

Carbon black particles have good electrical and thermal properties. They can be used to coat the surface of a textile to create heat-resistant fabric. Research has been done to develop an electrically conductive fabric. One study utilized cotton yarn coated with an electrically conductive black carbon-based solution (Negru et al., 2012).

Conductive adhesives are widely used in applications such as electronic packaging and solderfree connections, component repairs, and heat dissipation. Conductive adhesive is used to form a connection of sufficient strength between two surfaces, with electrical interconnection formed between the two bound surfaces. This dual function usually requires a composite with particles in the dispersion adhesive matrix isolation. Commonly used fillers are conductive carbon black, flake graphite, and micro- or nano-sized metal particles such as silver, nickel, copper, or aluminum. The special polymer matrix is made of epoxy, silicone, polyamide, or polyurethane. Epoxy adhesive substances can be filled with electrical conductors such as nickel powder, flakes, and filaments, silver powder, and copper powder. The material for this research was designed to be an electrically conductive composite (Sancaktar \& Bai, 2011).

Carbon nanotubes and chitosan were added to a solution of acetic acid at a controlled temperature of $100^{\circ} \mathrm{C}$. Platinum adsorption is better for carbon nanotubes modified by chitosan, the conductivity for carbon nanotubes that are modified larger than carbon nanotubes without modification. In addition, platinum adsorption and carbon nanotube conductivity increase for higher deacetylation rates (Wu, 2014).

The influence of pressure, volume, mechanical work, and carbon density were investigated. The 
decline in volume under compression depends significantly on any particular carbon and the pressure applied to it. The increase in conductivity by decreasing the sample volume is greater for carbon where the volume under compression is smaller. The increase in total conductivity is greater for the denser carbon and at least for the lightest. Both the conductivity and its variation in compression are positively related to carbon density. Six types of commercial carbon blacks were compacted, then measured for electrical conductivity properties (Sánchez-González et al., 2005). Methods have been investigated to detect damage by electrical resistance in carbon fiber polymer matrix composites. Rectangular panels or strips with electrode plates are generally used when measuring the conductivity of materials such as composite panels made of continuous carbon fiber and a polymer matrix. Surface electrical resistance and levels of conductivity through various thicknesses are obtained (Shen et al., 2007).

One experiment used particles of carbon black. The average size of primary carbon black particles is about $30 \mathrm{~nm}$. All specimens used in this research were ethylene butyl acrylate (EBA) copolymers filled with acetylene carbon black (Hasnaoui, 2011). The carbon black was provided by a manufacturer. Five specimens were prepared using the gravity casting method. Composites with epoxy resin as a matrix and the graphite as a filler were cast. Polymer composite material containing graphite was studied to observe the electrical properties of composites (Szczepanik et al., 2009).

The shell of apple wood used in this study was initially washed with water to remove dirt and then dried in an oven to remove the moisture. The dry shells were converted into a fine powder using a ball milling process and followed by sieve analysis to measure particle size. The goal was to develop a carbon black material from agricultural waste using pyrolysis at varied carbonization temperatures and to use it as a reinforcement in polymer composites (Ojha et al., 2015).

Due to the electrical conductivity of carbon black and the non-conductive nature of tar and sand, the addition of carbon black to pitch or asphalt is expected to decrease electrical resistance, especially when the volume of the carbon black exceeds the percolation threshold. One study aims to examine the thermal, mechanical, and electrical effects of adding carbon black to composite pitch. Research has shown the effects of adding the electrical properties of carbon black to decrease electrical resistivity (Wen \& Chung, 2004).

In 2011, a method was developed for measuring the electrical resistance of a single fiber made of carbon. The electrical resistivity or conductivity of fibers can be measured by using a simple electrical resistance probe. Variations of two and four probes are often used when measuring the resistivity of a sample material (Rebouillat \& Lyons, 2011). Phenolic resin and carbon fiber type $12 \mathrm{~K}$ have been used to make carbon composites. A study tested the mechanical properties of these composites (Sulaiman et al., 2008).

Bamboo charcoal powder was mixed with polypropylene (PP) and low-density polyethylene (LDPE) to form a composite. Bamboo powder was used as a filler, and polypropylene and lowdensity polyethylene were used as a matrix. The best quality bamboo charcoal was made from bamboo branches, shoots, and roots processed in pyrolysis at $1000^{\circ} \mathrm{C}$. The electrical resistivity of the PP/bamboo charcoal and LDPE/bamboo charcoal composite decreases as the charcoal's bamboo content increases. The electrical resistivity of both types of polyolefin charcoal/bamboo composites seems to be substantially reduced (Kittinaovarat \& Suthamnoi, 2009).

\section{EXPERIMENTAL SET-UP}

\subsection{Materials}

The study used Gigantochloa apus bamboo that was manually made into fibers with a diameter of $\leq 0.5 \mathrm{~mm}$. Bamboo fibers were carbonized in a continuous vacuum furnace at a temperature of $800^{\circ} \mathrm{C}$, at a speed of $4.2^{\circ} \mathrm{C} /$ minute, held for 120 minutes. 
The carbonization process was carried out through pyrolysis without using inert gas. The pyrolysis process required only an airtight tube without oxygen to produce electrically conductive carbon.

Carbonization at a temperature of $800^{\circ} \mathrm{C}$ eliminated non-carbon elements and created pores in the carbon fiber (Ojha et al., 2015). Phenolic resins were prepared by fabricators and commercially purchased, without prior customization. The densities of bamboo carbon fibers are $1.3 \pm 0.12 \mathrm{gram} / \mathrm{cm}^{3}$.

\subsection{Samples Preparation}

Carbon fibers were arranged in one direction, with weights determined to be $5 \%$ to $10 \%$ of the phenolic resin. The phenolic resin is poured into a mold measuring $10 \times 10 \times 120 \mathrm{~mm}$, with bamboo carbon fiber as a reinforcement. This process was conducted manually. The test specimen data are shown in Table 1, and the fabricated composite of carbon fibers and phenolic resin is shown in Figure 1.

Table 1 Test specimen

\begin{tabular}{lcccccc}
\hline \multirow{2}{*}{ Test } & \multicolumn{5}{c}{ Carbon fiber content, \% } \\
\cline { 2 - 7 } & 5 & 6 & 7 & 8 & 9 & 10 \\
\hline Electric conductivity & 5 & 5 & 5 & 5 & 5 & 5 \\
Tensile strength & 5 & 5 & 5 & 5 & 5 & 5 \\
Impact strength & 5 & 5 & 5 & 5 & 5 & 5 \\
\hline
\end{tabular}

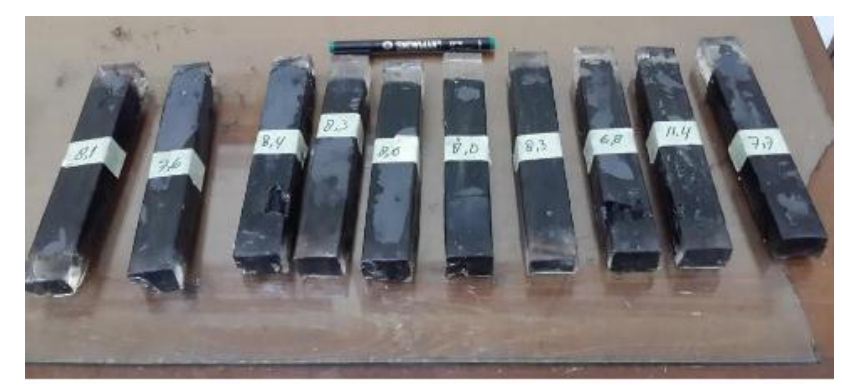

Figure 1 Test specimens

\subsection{Electrical Conductivity Test}

Electrical conductivity was measured with a two-point probe method (Celzard et al., 2002), following the American Society for Testing Materials (ASTM) standard D 578), by measuring the composite's electrical resistance. Static electric resistance was calculated with the following equation (Espinola et al., 1986; Sancaktar \& Bai, 2011; Saleem et al., 2010; Rebouillat \& Lyons, 2011; Shen et al., 2007):

$$
\rho=\mathrm{R} \times \mathrm{A} \times 1^{-1}[\Omega . \mathrm{m}]
$$

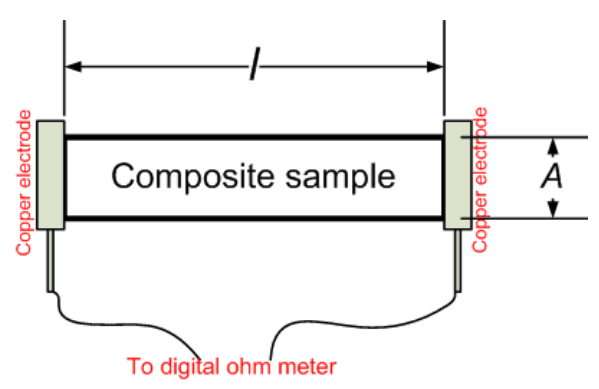

Figure 2 Two-point probe method 
where $\rho$ is the static resistance in $\Omega . \mathrm{m}, R$ is the electrical resistivity in $\Omega, A$ is the cross-sectional area in $\mathrm{m}^{2}$, and $l$ is the distance of resistivity in $\mathrm{m}$. Electrical conductivity is determined by the formula (Sánchez-González et al., 2005; Espinola et al., 1986):

$$
\sigma=1 \times \rho^{-1}[\Omega . \mathrm{m}]^{-1} \text { or in }\left[\text { Siemens. } m^{-1}\right]
$$

\subsection{Tensile Strength Test}

Tensile strength was tested with a tensile testing machine. The tensile strength of carbon fiber/phenolic resin composites was determined by the formula:

$$
\sigma=\mathrm{F} \times \mathrm{A}^{-1}\left[\mathrm{~N} \cdot \mathrm{mm}^{-2}\right]
$$

where $\mathrm{F}$ is the tensile test load in $\mathrm{N}$, and $\mathrm{A}$ is the cross-sectional area of the test specimen in $\mathrm{mm}^{2}$.

\subsection{Impact Strength Testing}

Impact strength testing followed the ISO standard 179/1U. The value of the impact strength was calculated by the following equation:

$$
\mathrm{a}_{\mathrm{cU}}=\mathrm{E}_{\mathrm{c}} \times(\text { h.b })^{-1} \times 10^{3}
$$

where $\mathrm{a}_{\mathrm{cU}}$ is Charpy un-notched impact strength $\left(\mathrm{kJ} \cdot \mathrm{m}^{-2}\right), \mathrm{E}_{\mathrm{c}}$ is the energy correction (joule) absorbed by the fracture of the test specimen, $h$ is the thickness $(\mathrm{mm})$ of the test specimen, and $b$ is the width $(\mathrm{mm})$ of the test specimen.

\subsection{Morphology Test}

The morphology of carbon fiber composites was examined with the scanning electron microscope (SEM) JEOL JSM-6390A.

\section{RESULTS AND DISCUSSION}

\subsection{Morphology of Composites}

Composite morphology testing was performed to observe the shape of a cross section of bamboo fiber, bamboo carbon fiber, carbon fiber interfaced with the phenolic matrix, and cracks in the composite. Composite morphology was observed with the SEM JEOL JSM-6390A test machine. Test parameters were as follows: Acquisition Parameter, Instrument: 6390 (LA); Acc. Voltage: 20.0 kV; Probe Current: 1.00000 nA; PHA mode: T4. Composite specimens with $10 \%$ carbon fiber content were used as a composite morphology specimen because the sample has the highest electrical conductivity. Morphological test results are shown in Figure 3.

Morphology pictures with $700 \times$ magnification show cross-sectional shapes of bamboo carbon fiber bonded to the phenolic resin. Carbon fiber bamboo shows visible parenchymal tissue of the bamboo carbon in an irregular hexagon shape. Meanwhile, phenolic resin is flat, without any holes or cavities, as shown in Figure 3a. The cross section of bamboo carbon fiber magnified $2000 \times$ clearly shows holes in parenchymal tissue of bamboo carbon fiber, as shown in Figure $3 \mathrm{~b}$. The cracks in the interface between bamboo carbon fibers and phenolic resin is shown in Figure $3 c$ in $200 \times$ magnification. The cross section shows the honeycomb-like parenchymal tissue of bamboo carbon fiber, while other parts show phenolic resin as a matrix. Figure $3 \mathrm{~d}$ shows the fibers before carbonization, highlighting a cross section of real vascular bundles with Gigantochloa apus fibers at a magnification of 1500x. The bamboo fiber cross section shows the irregular hexagon shape. This can be compared with the already carbonized bamboo fibers. 


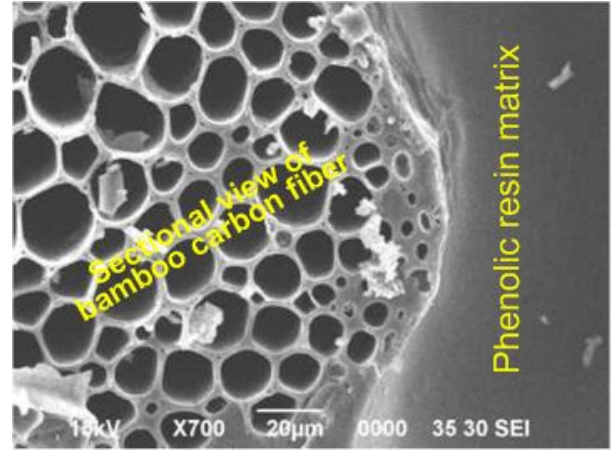

(a)

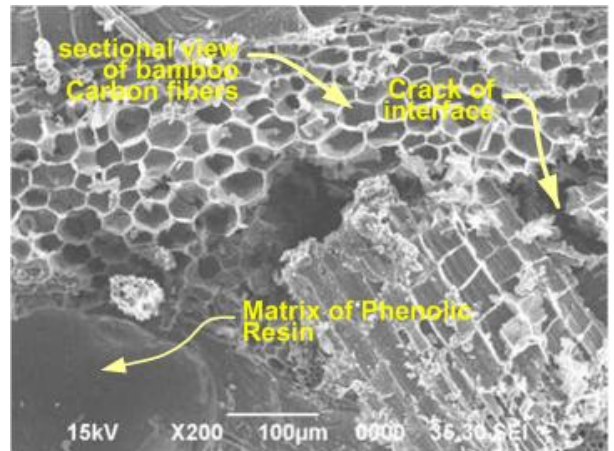

(c)

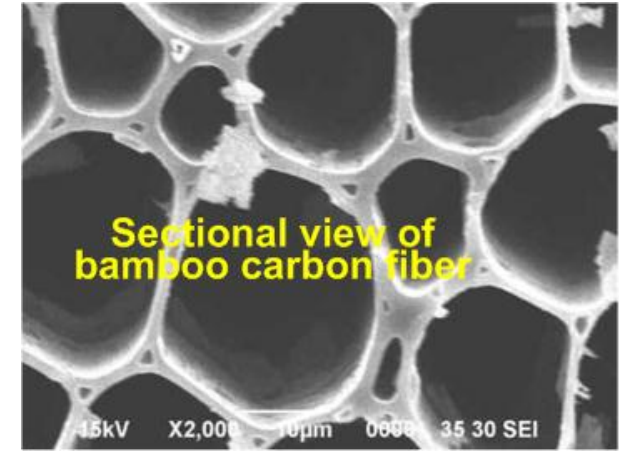

(b)

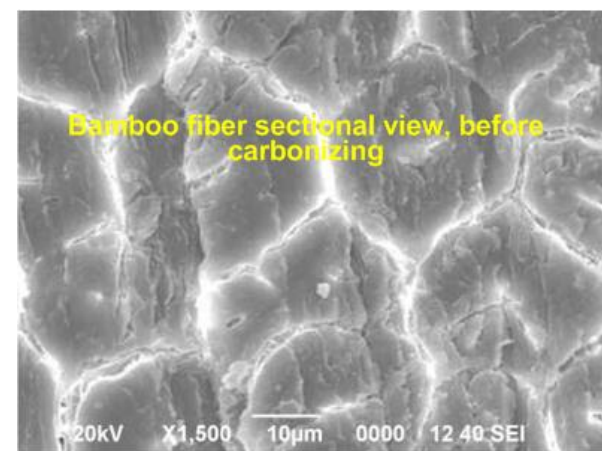

(d)

Figure 3 Morphology: (a) Morphology of composite; (b) Morphology of bamboo carbon fiber; (c) Cracks in the composite; (d) Bamboo fiber cross section before carbonizing

Occasionally air is trapped in the resin at the time of casting, leading to cracks and cavities in the composite. Reaction between the phenolic resin and hardener catalyst produce heat, causing the trapped air to increase in pressure, and break in between the fibers. This results in cracks in the interface between the carbon fiber and phenolic resin. The crack weakens the mechanical properties of such composites. The cracks also cause breaking of the carbon fiber braid in the composite, causing weak electrical conductivity. Test results show this instability of electrical conductivity in the composite. When the air bubble bursts between carbon fibers, the carbon fiber braid will break up, and cause electrical resistance in the composite. Not all carbon fiber in phenolic resin disconnects; most still forms the strands that can become electrically conductive. This inconsistency is the cause of the electrical conductive instability in the composite.

\subsection{Electrical Conductivity}

Electrical conductive testing data were obtained by measuring electrical resistance, sample length, and cross-sectional areas. The measurement technique is shown in Figure 2. There were five specimens measured with each carbon content variation. The electrical conductivity was determined by Equation 2. Electrical conductivity data were connected with the percentage of carbon content in the composite to determine the best electrical conductivity based on carbon fiber content. Figure 4 shows that the higher the percentage of carbon fiber content, the higher the electrical conductivity of a carbon fiber/phenolic resin composite. The highest electrical conductivity is generated by composites containing $10 \%$ carbon fiber weight. The highest electrical conductivity is generated by composites containing $10 \%$ carbon fiber weight. In this composite also yields the highest tensile strength. As shown in Figure 5.

The results of the 2009 study suggested that adding of the volume of graphite to the epoxy resin causes a decrease in electrical surface resistivity (Szczepanik et al., 2009). A carbon fiber content

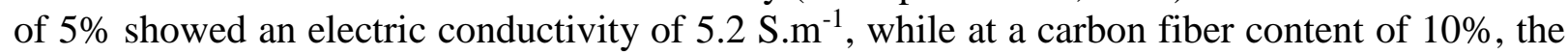
electrical conductivity reached $51.12 \mathrm{~S} . \mathrm{m}^{-1}$. A study stated that carbon black particles have good 
electrical properties (Negru et al., 2012). Electricity can only pass through a material if there is a sufficient conducting network of fillers that are electrically conductive (Saleem et al., 2010).

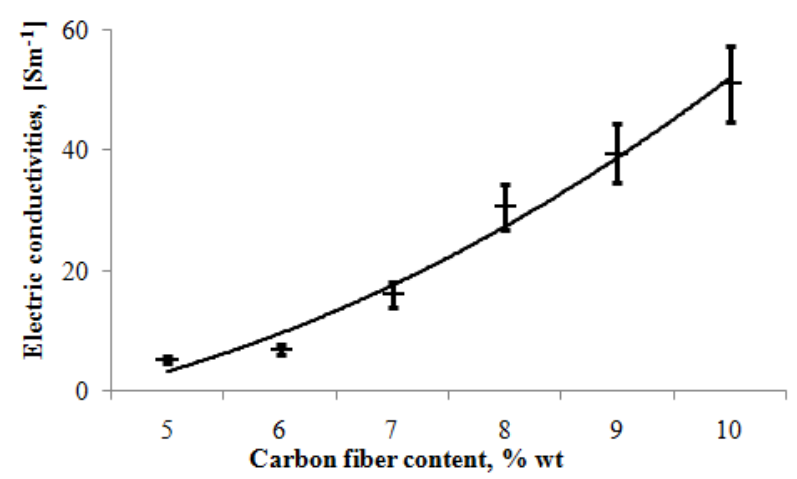

Figure 4 The relationship of electrical conductivity $v s$ carbon fiber content

Deviations are likely to be caused by nonhomogeneous interconnections of carbon fiber, resulting in voids between fibers. Phenolic resin as a matrix in these composites is not electrically conductive (Szczepanik et al., 2009), so when it fills the gaps dissolution of carbon fiber will increase the flow resistance. Research shows that electrical conductivity depends on the number of effective electrical contacts formed between carbon particles (Sánchez-González et al., 2005). Irregularities cause unstable flow of electricity in the composite as a whole due to cracks or cavities. This can be seen through the results of the morphology test.

\subsection{Tensile strength}

The composite tensile strength test was conducted by a universal testing machine., universal testing machine (UTM), Tarno testing, TARNOGROCKI, GA 0.3V/483, following ASTM D 3039-76 (Ojha et al., 2015). Five specimens were tested to show each variation of carbon fiber content. This test provided load test data. The tensile strength of the test sample was determined by Equation 3. The composite tensile strength was related to the percentage of carbon fiber content in the composite, to determine the highest tensile strength based on carbon fiber content, as shown in Figure 5.

The increase in carbon fiber content tends to increase the tensile strength of these composites, but this effect is not stable. A carbon fiber content of $5 \%$ has a tensile strength of $9 \mathrm{~N} / \mathrm{mm}^{2}$, but when the carbon fiber content increased from $6 \%$ to $9 \%$, composite tensile strength decreased. When fiber content increased again to $10 \%$, the tensile strength increased to $12 \mathrm{~N} / \mathrm{mm}^{2}$, as shown in Figure 5. Tensile strength instability was caused by cavities formed in the phenolic resin matrix, and at the interface between the fiber and the resin matrix. In the curing process, some physical and chemical changes occur when the material changes from viscous to hard solid (Sulaiman et al., 2008).

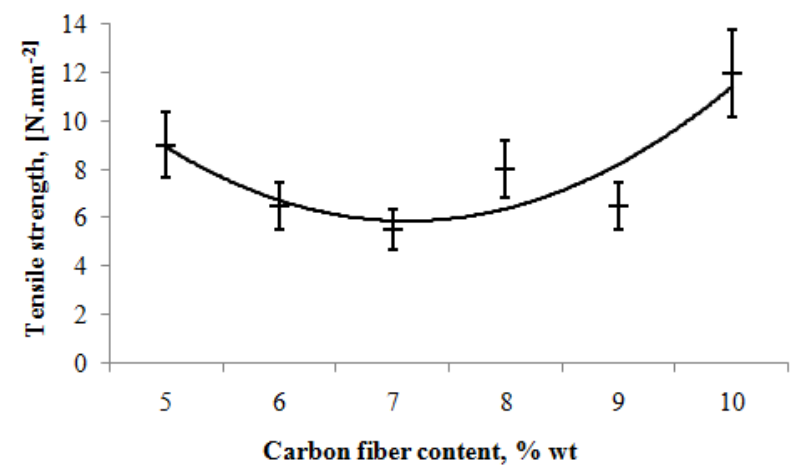

Figure 5 The relationship of tensile strength $v s$ carbon fiber content 
The distribution and orientation of carbon fibers and the matrix affects the tensile strength properties of composites. One cause of weakness in the mechanical properties of composites were most likely the chemical reactions at the interface between carbon fiber. These made the matrix too weak to move the tensile load (Ojha et al., 2015). This condition can be proven through testing composite morphology with SEM testing.

\subsection{Impact Strength}

Five specimens were used in the impact strength test specimen with each variation of carbon fiber content represented. The impact strength test followed ISO 179/1U standards. Specimens underwent Charpy impact testing, un-notched, conditioned at a temperature of $23.3^{\circ} \mathrm{C}$ with $42.0 \%$ humidity for 48 hours. The test used a $2 \mathrm{~J}$ pendulum impact tester with an impact speed of 2.9 $\mathrm{m} / \mathrm{s}$. The test was conducted using the CEAST Resil impact machine. The impact strength value of the composite was determined by Equation 4. Impact strength was compared to the percentage of carbon fiber in the composite to determine the highest impact strength of the composites based on the percentage of carbon fiber. This is shown in Figure 6.

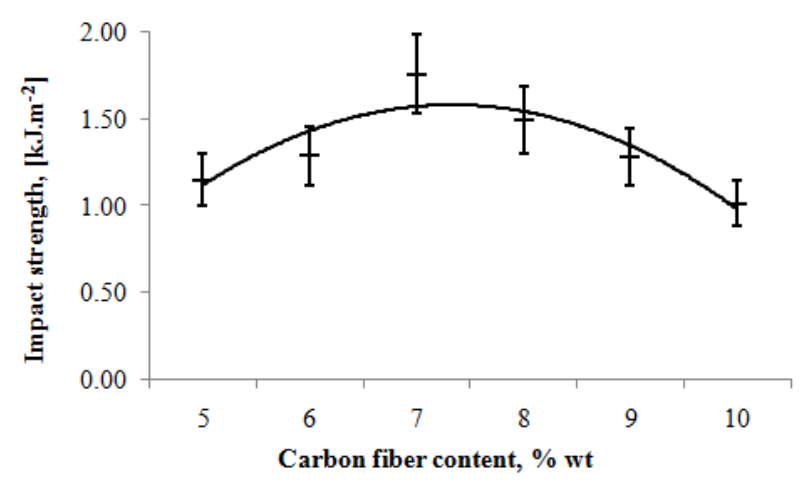

Figure 6 The relationship of impact strength $v s$ carbon fiber content

Impact strength of composites were unstable. Composites with a $7 \%$ weight content of carbon fibers showed strength of $1.76 \mathrm{~kJ} \cdot \mathrm{m}^{-2}$. Meanwhile, carbon fiber composites containing $5 \%$ weight showed $1.15 \mathrm{~kJ} \cdot \mathrm{m}^{-2}$. When the carbon fiber content increased to $10 \%$ by weight, impact strength decreased to $1.02 \mathrm{~kJ} \cdot \mathrm{m}^{-2}$. This shows the impact strength of bamboo carbon fiber and phenolic resin composites in this study is not stable. This is affected by cavities formed in the phenolic resin composites when casting into molds.

\section{CONCLUSION}

Research has been conducted on the electrical conductivity and mechanical properties of bamboo carbon fiber/phenolic resin composites or bamboo carbon fiber reinforced polymer (BCFRP) composites. The higher the percentage of carbon fiber in a composite, the higher the electrical conductivity of the composite. Increased carbon fiber in a composite tends to increase the tensile strength of these composites. This study found instabilities in the impact strength of bamboo carbon fiber and phenolic resin composites.

For application with a combination of high electrical conductivity and tensile strength, a composite of $10 \%$ carbon fiber content may be used. However, this type of composite is not resistant to impact loads.

The cracks are also the cause of breaking carbon fiber braids in the composite, resulting in weak electric current conductivity. Some fibers remain intact, but the frequent breakage leads to electrical instability. Local natural fiber is widely available, in the future can also be developed 
carbonization of organic natural fibers from sisal, coconut fiber, and organic waste, as electrically conductive fillers.

\section{ACKNOWLEDGEMENT}

The authors wish to thank the Directorate of Research and Community Service, the Directorate General of Higher Education, and the Ministry of Engineering Research and Higher Education of the Republic of Indonesia for funding this work. This research was funded through a national research strategy with the contract number: 089/SP2H/PL/Dit.Litabmas/II/2015.

\section{REFERENCES}

Celzard, A., Marêché, J.F., Payot, F., Furdin, G., 2002. Electrical Conductivity of Carbonaceous Powders. Carbon, Volume 40(15), pp. 2801-2815

Espinola, A., Miguel, P.M., Salles, M.R., Pinto, A.R., 1986. Electrical Properties of Carbonsresistance of Powder Materials. Carbon, Volume 68, pp. 276-281

Hasnaoui, M.El., 2011. Electric Modulus Analysis of Carbon Black/Copolymer Composite Materials. Materials Sciences and Applications, Volume 2(10), pp. 1421-1426

Kittinaovarat, S., Suthamnoi, W., 2009. Physical Properties of Polyolefin/Bamboo Charcoal Composites. Journal of Metals, Materials and Minerals, Volume 19(1), pp. 9-15

Lonjon, A., Demont, P., Dantras, E., Lacabanne, C., 2012. Electrical Conductivity Improvement of Aeronautical Carbon Fiber Reinforced Polyepoxy Composites by Insertion of Carbon Nanotubes. Journal of Non-Crystalline Solids, Volume 358(15), pp. 1859-1862

Negru, D., Buda, C.T., Avram, D., 2012. Electrical Conductivity of Woven Fabrics Coated with Carbon Black Particles. FIBRES \& TEXTILES in Eastern Europe, Volume 1(90), pp. 53-56

Ojha, S., Acharya, S.K., Raghavendra, G., 2015. Mechanical Properties of Natural Carbon Black Reinforced Polymer Composites. Journal of Applied Polymer Science, Volume 132(1), pp. $1-7$

Rebouillat, S., Lyons, M.E.G., 2011. Measuring the Electrical Conductivity of Single Fibres. International Journal of Electrochemical Science, Volume 6(11), pp. 5731-5740

Saleem, A., Frormann, L., Soever, A., 2010. Fabrication of Extrinsically Conductive Silicone Rubbers with High Elasticity and Analysis of their Mechanical and Electrical Characteristics. Polymers, Volume 2(3), pp. 200-210

Sancaktar, E., Bai, L., 2011. Electrically Conductive Epoxy Adhesives. Polymers, Volume 3(1), pp. 427-466

Sánchez-González, J., Macias-Garcia, A., Alexandre-Franco, M.F., Gomez-Serrano, V., 2005. Electrical Conductivity of Carbon Blacks under Compression. Carbon, Volume 43(4), pp. 741-747

Shen, L., Li, J., Liaw, B.M., Delale, F., Chung, J.H., 2007. Modeling and Analysis of the Electrical Resistance Measurement of Carbon Fiber Polymer-matrix Composites. Composites Science and Technology, Volume 67(11-12), pp. 2513-2520

Sulaiman, S., Yunus, R., Ibrahim, N.A., Rezaei, F., 2008. Effect of Hardener on Mechanical Properties of Carbon Fibre Reinforced Phenolic Resin Composites. Journal of Engineering Science and Technology, Volume 3(1), pp. 79-86

Szczepanik, M., Stabik, J., Lazarczyk, M., Dybowska, A., 2009. Influence of Graphite on Electrical Properties of Polymeric Composites. Archives of Materials Science and Engineering, Volume 37(1), pp. 37-44

Wen, S., Chung, D.D.L., 2004. Effects of Carbon Black on the Thermal, Mechanical and Electrical Properties of Pitch-matrix Composites. Carbon, Volume 42(12-13), pp. 23932397 
Wu, H., 2014. Adsorption and Electrical Conductive Properties of Carbon Nanotube Modified by Chitosan. Journal of Materials Science and Engineering A, Volume 4(3), pp. 83-90 